\title{
KEPADATAN JAMUR MIKORIZA VESIKULAR ARBUSKULAR (MVA) DI KAWASAN HUTAN MANGROVE DESA PENITI KABUPATEN MEMPAWAH KALIMANTAN BARAT
}

\author{
Hartini $^{1}$, Riza Linda ${ }^{1}$, Rahmawati ${ }^{1}$ \\ ${ }^{1}$ Program Studi Biologi, Fakultas MIPA, Universitas Tanjungpura, \\ ${ }^{1}$ Prof. Dr. H. Hadari Nawawi, Pontianak, 78124 \\ email korespondensi : nhartiniahmad@gmail.com
}

\begin{abstract}
Mycorrhizal fungi are fungi that are associated with higher levels of plants and are very important in plant growth. Mycorrhizal fungi can be found most of the land, one of which is in the mangrove forest. This study was conducted to determine the type of fungus and the percentage of infections in plant roots and fungal density of VAM found in the Mangrove Forest area at Mempawah Regency, West Kalimantan. This research was conducted at the Microbiology Laboratory of the Department of Biology, Faculty of Mathematics and Natural Sciences. Analysis of soil chemical content was carried out in the Laboratory of Chemical and Soil Fertility, Faculty of Agriculture, Tanjungpura University. Isolation of spores was carried out by wet filter method and continued with centrifugation. The results indicated that the spores found consisted of 3 genera were Glomus, Gigaspora and Paraglomus. The percentage of root infections by mycorrhizal fungi was classified as low at $10.65 \%$, and density of VAM fungus spores in Parit Tanjung as many 13 spores, Kasim as many 10 spores, Sungai Burung as many 59 spores and Tanjung as many 33 spores.
\end{abstract}

Keywords: Density, Vesicular Arbuscular Mycorrhiza (VAM), Mangrove

\section{PENDAHULUAN}

Jamur mikoriza vesikular arbuskular (MVA) merupakan simbiosis mutualisme antara jamur dengan akar tumbuhan. Menurut Smith dan Read (2008), hubungan simbiosis antara akar dan tumbuhan terjadi saling menguntungkan, jamur mendapatkan karbohidrat dan unsur pertumbuhan lainnya dari tanaman inang, sebaliknya jamur membantu tanaman inang dalam menyerap unsur hara makro dan mikro.

Menurut Nursanti et al., (2012), jamur mikoriza dapat ditemukan hampir pada sebagian besar tanah dan pada umumnya tidak mempunyai tanaman inang yang spesifik. Nadarajah dan Nawawi (1997) juga menyatakan bahwa jamur mikoriza dapat dijumpai dalam beberapa ekosistem darat seperti semak, padang rumput, dan hutan hujan tropika. Jamur mikoriza juga ditemukan pada ekosistem hutan mangrove seperti penelitian yang dilakukan oleh Nursanti et al., (2012), yang mengidentifikasi jamur Mikoriza di Hutan Lindung Mangrove Pangkal Babu Jambi menemukan kepadatan spora terendah yaitu 15-19 spora per 100 gram tanah dan kepadatan tertinggi 58 spora per 100 gram tanah.
Setiap ekosistem mempunyai kemungkinan dapat mengandung jamur MVA dengan jenis yang sama atau bisa juga berbeda, karena keanekaragaman dan penyebaran jamur MVA sangat bervariasi yang disebabkan oleh kondisi lingkungan yang bervariasi juga, begitu pula dengan jamur MVA yang terdapat di hutan mangrove. Penelitian Gustian, et al. (2015) tentang asosiasi fungi Mikoriza Arbuskular pada Avicennia spp. di Desa Terusan ditemukan 3 jenis spora MVA yang terdiri dari Acaulospora, Glomus, dan Gigaspora.

Kalimantan Barat memiliki sebaran hutan mangrove yang luas, salah satunya hutan mangrove di Desa peniti, Kabupaten Mempawah. Vegetasi mangrove di Desa Peniti, Kabupaten Mempawah didominasi spesies Avicennia (Budiman, 2012). Keberadaan dan jenis jamur mikoriza di kawasan hutan mangrove Desa Peniti Kabupaten Mempawah Kalimantan Barat hingga saat ini belum diketahui, sehingga perlu dilakukan eksplorasi dan identifikasi. 


\section{BAHAN DAN METODE}

\section{Waktu dan Tempat Penelitian}

Penelitian dilaksanakan dari bulan Juli hingga Oktober 2017. Sampel diambil di Kawasan Hutan Mangrove Desa Peniti Kabupaten Mempawah Kalimantan Barat. Isolasi dan Identifikasi dilaksanakan Laboratorium Mikrobiologi Jurusan Biologi Fakultas Matematika dan Ilmu Pengetahuan Alam Universitas Tanjungpura Pontianak.

\section{Bahan}

Bahan yang digunakan dalam penelitian ini adalah akuades, glukosa $60 \%, \mathrm{HCl} 2 \%, \mathrm{H}_{2} \mathrm{O}_{2} 30 \%, \mathrm{KOH}$ $10 \%$, laktogliserol, melzer, $\mathrm{NaClO} 5,25 \%$, sampel tanah dan akar Avicennia dan trypan blue.

\section{Prosedur Kerja}

\section{Pengambilan sampel}

Sampel akar dan tanah diambil pada 4 lokasi yang berbeda. Setiap lokasi pengambilan sampel terdapat masing-masing tiga titik pengambilan. Proses pengambilan sampel tanah dan akar dilakukan secara acak disekitar perakaran dengan kedalaman 0-20 cm. Sampel yang diambil merupakan komposit dari tiga titik, masing-masing titik diambil sebanyak 100 gram tanah. Sampel pada tiap lokasi dilakukan pengulangan sebanyak 3 ulangan, sehingga jumlah sampel keseluruhan sebanyak 12 sampel tanah dan 12 sampel akar (Warouw dan Reynold, 2010).

\section{Isolasi Spora Jamur MVA}

Isolasi spora jamur MVA dilakukan dengan menggunakan metode kombinasi antara teknik tuang saring basah (Pacioni, 1992) dan teknik sentrifugasi (Brundrett et al., 1996) dengan tahapan $100 \mathrm{~g}$ per sampel, kemudian dilarutkan ke dalam $300 \mathrm{ml}$ akuades dan diaduk hingga homogeny. Kemudian di saring dengan saringan bertingkat dengan ukuran $850 \mu \mathrm{m}$ (saringan kasar), $300 \mu \mathrm{m}$ (saringan sedang) dan $63 \mu \mathrm{m}$ (saringan halus). Hasil saringan terakhir dipindahkan ke dalam tabung sentrifuse dan ditambahkan glukosa $60 \%$ sebanyak $10 \mathrm{ml}$. Setelah itu disentrifugasi dengan kecepatan $2000 \mathrm{rpm}$ selama 5 menit. Proses sentrifugasi ini akan menghasilkan 2 fase yaitu larutan supernatan (bening) dan endapan (keruh). Larutan supernatan yang terbentuk

$$
\% \text { Infeksi akar }=\frac{\sum \text { Akar yang terinfeksi }}{\sum \text { Akar yang diamati }} \times 100 \%
$$

diambil dan diletakkan di atas cawan petri dan diamati di bawah mikroskop.

Identifikasi spora

Identifikasi jamur MVA dilakukan berdasarkan karakteristik ciri-ciri umum dari spora yang ditemukan meliputi bentuk spora, warna spora, jumlah dinding spora, reaksi spora ketika diberi larutan melzer. Spora yang ditemukan dicatat karakteristiknya dan diambil gambarnya. Karakterisasi spora jamur MVA dilakukan dengan menggunakan buku identifikasi jamur mikoriza menurut Schenck dan Perez (1990) yang berjudul 'Manual for identification on VA Mycorryza Fungi' dan International Culture Collection of (Vesicular) Arbuscular Mycorrhizal Fungi (INVAM, 2018).

\section{Pewarnaan dan Pembuatan Preparat Akar}

Akar dicuci terlebih dahulu dengan air mengalir sampai bersih dari kotoran kemudian dipotong menjadi 30 bagian dengan ukuran $\pm 1 \mathrm{~cm}$. Akar direndam dengan larutan $\mathrm{NaClO} 5,25 \%$ selama 5 menit, lalu dibilas dengan akuades. Kemudian akar direndam dengan larutan $\mathrm{KOH} 10 \%$ dan dipanaskan pada suhu $60{ }^{\circ} \mathrm{C}$, kemudian dibilas dengan akuades. Setelah itu akar di rendam dengan larutan $\mathrm{H}_{2} \mathrm{O}_{2} 30 \%$ sampai terlihat bening kemudian dibilas dengan akuades. Selanjutnya akar direndam dengan larutan $\mathrm{HCl} 2 \%$ selama 5 menit. Akar direndam dengan larutan trypan blue selama 10 menit, kemudian dibilas dengan akuades. Akar kemudian direndam dengan larutan laktogliserol selama 5 menit, kemudian dibilas dengan akuades dan disusun dpada gelas objek kemudian diamati dibawa mikroskop (Warouw dan Reynold, 2010).

\section{Variabel Pengamatan}

Variabel pengamatan meliputi jenis jamur MVA, jumlah spora jamur MVA, persentase tingkat infeksi jamur MVA, kepadata spora jamur MVA, kelembaban tanah, $\mathrm{pH}$ tanah, suhu udara, suhu tanah, kadar $\mathrm{N}$ total, $\mathrm{P}$ tersedia, $\mathrm{C}$ organik dan KTK.

\section{Pengolahan Data}

Jumlah spora jamur dari setiap sampel tanah yang diperoleh akan disajikan dalam bentuk tabel dan foto. Kepadatan spora dihitung berdasarkan jumlah spora yang ditemukan per 100 gram tanah. Persentase akar yg terinfeksi dihitung berdasarkan rumus berikut (Setiadi, 2001): 
Tingkat infeksi akar ditentukan berdasarkan kelas infeksi akar, yang terdiri dari Setiadi (2001) :

Kelas 1, infeksi akar 0\% - 5\% (sangat rendah)

Kelas 2, infeksi akar 6\% - 25\% (rendah)

Kelas 3, infeksi akar 26\% - 50\% (sedang)

Kelas 4, infeksi akar 51\% - 75\% (tinggi)

Kelas 5, infeksi akar 76\%-100\% (sangat tinggi)

\section{HASIL DAN PEMBAHASAN}

\section{Hasil}

Genus dan Jumlah Spora MVA

Berdasarkan hasil penelitian, pada sampel tanah di kawasan hutan mangrove desa peniti ditemukan 3 anggota genus jamur MVA yaitu Glomus, Gigaspora, dan Paraglomus (Tabel 1).

Tabel 1. Genus dan jumlah spora MVA pada 4 lokasi dikawasan hutan mangrove peniti

\begin{tabular}{|c|c|c|c|c|}
\hline \multirow{2}{*}{ Lokasi } & \multicolumn{3}{|c|}{ Jumlah spora } & \multirow{2}{*}{ Jumlah } \\
\hline & Glomus & Gigaspora & Paraglomus & \\
\hline $\begin{array}{c}\text { Parit } \\
\text { Tanjung }\end{array}$ & 12 & 0 & 1 & 13 \\
\hline Kasim & 10 & 0 & 0 & 10 \\
\hline $\begin{array}{l}\text { Sungai } \\
\text { Burung }\end{array}$ & 55 & 4 & 0 & 59 \\
\hline Tanjung & 32 & 0 & 1 & 33 \\
\hline Jumlah & 109 & 4 & 2 & 115 \\
\hline
\end{tabular}

Hasil yang tertera pada tabel 1 menunjukkan bahwa spora paling banyak ditemukan di Sungai Burung yaitu 59 spora, sedangkan jumlah spora paling sedikit ditemukan di Kasim yaitu 10 spora. Jumlah spora yang mempunyai jumlah paling banyak yaitu anggota genus Glomus dengan jumlah 109 spora, sedangkan yang paling sedikit yaitu anggota genus Paraglomus dengan jumlah 2 spora.

Persentase Tingkat Infeksi Jamur MVA pada Akar Persentase infeksi jamur MVA pada perakaran tanaman Avicennia dapat dilihat pada Tabel 3.

Tabel 2. Persentase Tingkat Infeksi Jamur MVA Pada Perakaran Avicennia

\begin{tabular}{cc}
\hline Lokasi & $\begin{array}{c}\text { Persentase Akar Yang } \\
\text { Terinfeksi }(\%)\end{array}$ \\
\hline Parit Tanjung & $9 \%$ \\
Kasim & $11,3 \%$ \\
Sungai Burung & $8 \%$ \\
Tanjung & $14,3 \%$ \\
\hline Jumlah & $42,6 \%$ \\
\hline Rerata & $10,65 \%$ \\
\hline
\end{tabular}

Berdasarkan Tabel 2 rerata persentase tingkat infeksi jamur MVA pada perakan Avicennia sebesar $10,65 \%$ dan tergolong ke dalam kategori tingkat rendah.

\section{Pengukuran Faktor Lingkungan}

Hasil pengukuran faktor lingkungan pada masingmasing lokasi tertera pada Tabel 3.

Tabel 3. Pengukuran Faktor Lingkungan di Kawasan Hutan Mangrove Desa Peniti

\begin{tabular}{|c|c|c|c|c|}
\hline \multirow{2}{*}{ Faktor Lingkungan } & \multicolumn{4}{|c|}{ Lokasi } \\
\hline & Parit Tanjung & Kasim & Sungai Burung & Tanjung \\
\hline C-Organik (\%) & 6,88 & 6,51 & 3,23 & 3,05 \\
\hline N-Total (\%) & 0,74 & 0,72 & 0,37 & 0,34 \\
\hline $\mathrm{P}(\mathrm{Ppm})$ & 43,82 & 27,77 & 14,88 & 22,42 \\
\hline $\mathrm{KTK}\left(\mathrm{cmol}(+) \mathrm{kg}^{-1}\right)$ & 27,03 & 25,83 & 12,10 & 11,75 \\
\hline $\mathrm{pH}$ & 7 & 6,9 & 7 & 6,9 \\
\hline Kelembaban (\%) & 58 & 42 & 52 & 58 \\
\hline Suhu Udara $\left({ }^{\circ} \mathrm{C}\right)$ & 32 & 40 & 36 & 34 \\
\hline \multicolumn{5}{|c|}{$\begin{array}{ll}\text { Karakteristik Spora Genus Jamur } & \text { ditetesi larutan Melzer. Bentuk spora yang } \\
\text { Jamur MVA yang ditemukan di Kawasan Hutan } & \text { ditemukan antara lain adalah bulat dan bulat telur. } \\
\text { Mangrove Desa Peniti memiliki perbedaan } & \text { Warna spora antara lain merah, merah bata dan } \\
\text { karakter morfologi spora yang terdiri atas bentuk, } & \text { bening. Jumlah dinding spora rata-rata 1-2 dinding } \\
\text { warna, jumlah dinding, dan reaksi spora ketika } & \text { (Gambar 1). }\end{array}$} \\
\hline
\end{tabular}




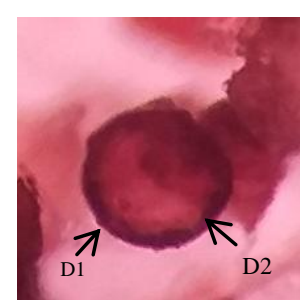

A

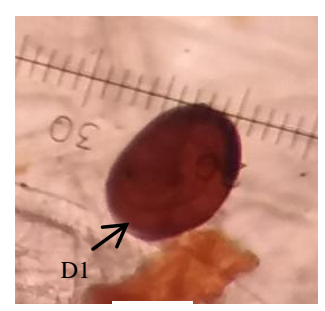

B

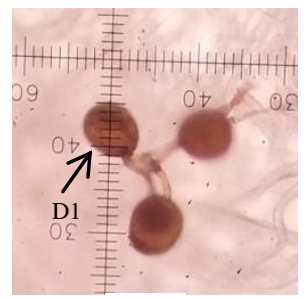

$\mathrm{C}$

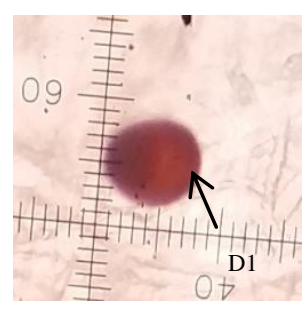

$\mathrm{D}$

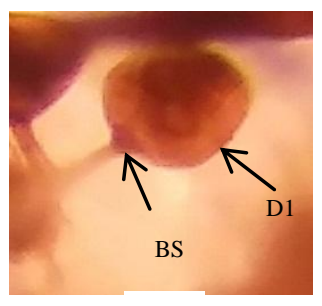

$\mathrm{E}$

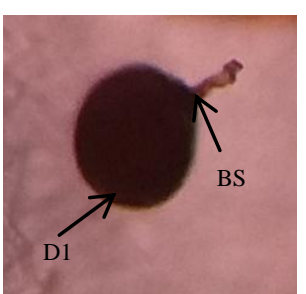

$\mathrm{F}$

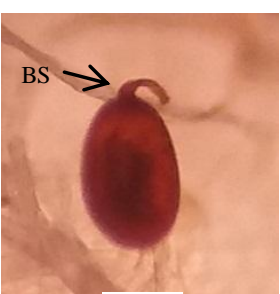

G

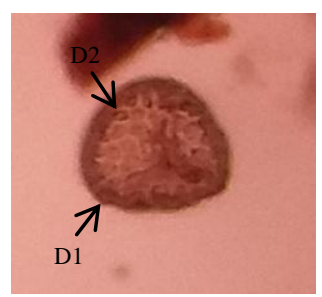

$\mathrm{H}$

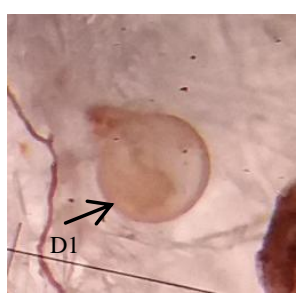

I

Gambar 1. Spora Genus MVA yang ditemukan pada tiap lokasi dikawasan Hutan Mangrove Peniti (perbesaran 100x), (A-D) Genus Glomus, (E-G) Genus Gigaspora (H-I) Genus Paraglomus

Keterangan: BS: Bulbous suspensor

D1: Dinding lapisan 1

D2: Dinding lapisan 2

\section{PEMBAHASAN}

Genus dan Jumlah Jamur MVA yang Ditemukan Jumlah dan jenis genus jamur MVA yang ditemukan pada suatu lokasi dipengaruhi oleh kondisi lingkungan. Hasil penelitian menunjukkan bahwa di kawasan Hutan Mangrove Desa Peniti di temukan 3 anggota genus spora jamur yaitu Glomus, Gigaspora dan Paraglomus. Hasil penelitian Gustian (2015) dikawasan Hutan Mangrove Desa Terusan Kecamatan Mempawah Hilir ditemukan anggota genus Glomus, Gigaspora dan Acaulospora. Hal ini menunjukkan bahwa anggota genus Glomus dan Gigaspora dapat berkembang dikawasan hutan mangrove.

Anggota genus yang paling banyak ditemukan di kawasan Hutan Mangrove Desa Peniti adalah anggota genus Glomus yaitu 109 spora. Anggota genus Glomus ditemukan di keempat lokasi yaitu Parit Tanjung, Kasim, Sungai Burung dan Tanjung (Tabel 1). Hal ini menunjukkan bahwa anggota genus Glomus mempunyai kemampuan bersimbiosis dan tingkat adaptasi yang cukup tinggi terhadap berbagai kondisi lingkungan. Anggota genus yang paling sedikit ditemukan jumlahnya yaitu anggota genus Paraglomus yaitu 2 spora. Menurut Brundrett et al. (1996) menyatakan bahwa genus Glomus mempunyai tingkat adaptasi yang sangat baik terhadap berbagai kondisi lingkungan dibandingkan dengan beberapa anggota genus jamur MVA lainnya. Hal tersebut dapat memungkinkan anggota genus Glomus banyak ditemukan di kawasan hutan mangrove peniti. Sieverding (1991) juga menyatakan bahwa anggota genus Glomus mempunyai ketahanan yang lebih tinggi dibandingkan dengan anggota genus yang lainnya.

Status jamur mikoriza di dalam tanah dapat dilihat dari kepadatan spora per gram tanah. Kepadatan spora jamur mikoriza dalam hal ini dilihat berdasarkan jumlah spora jamur mikoriza per 100 gram sampel tanah. Kepadatan spora jamur MVA di kawasan hutan mangrove desa peniti bervariasi. Kepadatan spora yang ditemukan pada lokasi Parit Tanjung sebanyak 13 spora, pada lokasi Kasim sebanyak 10 spora, pada lokasi Sungai Burung sebanyak 59 spora dan pada lokasi Tanjung sebanyak 33 spora. Jumlah spora jamur MVA pada hutan mangrove dipengaruhi terutama oleh kondisi kimia tanah dan lingkungan dari sampel tanah hutan mangrove tersebut. Menurut Daniels dan skipper (1982) populasi jamur MVA pada tanah dikatakan tinggi apabila kepadatan spora sebanyak 20 spora per gram tanah. Berdasarkan pendapat tersebut kepadatan spora di Kawasan Hutan Mangrove Desa Peniti tergolong rendah.

Jumlah kepadatan spora sangat dipengaruhi oleh faktor lingkungan seperti suhu. Suhardi (1990) 
menyatakan bahwa suhu berpengaruh terhadap terbentuknya koloni dan meningkatkan produksi spora jamur MVA. Berdasarkan hasil pengukuran di lapangan, suhu udara berkisar antara $32-40{ }^{\circ} \mathrm{C}$ (Tabel 3). Hal ini mengakibaktan jumlah spora yang ditemukan tiap lokasi hanya sedikit, sedangkan suhu udara yang optimal untuk pertumbuhan spora jamur MVA menurut Nurhalimah et al. (2014) adalah $18-25^{\circ} \mathrm{C}$.

Perkembangan spora mikoriza dipengaruhi oleh banyak faktor yang saling berhubungan. Selain suhu udara $\mathrm{pH}$ tanah juga memiliki pengaruh terhadap keberadaan jamur MVA. Nilai $\mathrm{pH}$ tanah pada lokasi penelitian bekisar antara 6,9-7,0 dan tergolong netral (Pusat Penelitian Tanah, 1983). Kondisi $\mathrm{pH}$ tanah yang netral membuat spora jamur MVA pada lokasi penelitian yang ditemukan sedikit, sedangkan spora jamur MVA hidup baik dalam kondisi tanah yang masam. Menurut Setiadi (1992) perkembangan jamur MVA yang optimal berkisar pada $\mathrm{pH}$ 3,9-5,9.

Faktor lain yang memengaruhi jumlah spora adalah kelembaban tanah dan $\mathrm{P}$ tersedia. Berdasarkan hasil kelembapan tanah pada lokasi tergolong tinggi yaitu 42-58\% (Tabel 3). Hal ini mengakibatkan sedikitnya jumlah spora yang ditemukan pada lokasi penelitian. Nurhalimah et al. (2014) menyatakan bahwa kelembapan tanah yang tinggi mengakibatkan jumlah spora yang tersedia sedikit. Menurut Burhanudin (2012) pada kondisi tanah yang lembab, proses pembentukan spora jamur MVA menjadi lebih rendah sehingga jumlah spora yang terkandung dalam tanah juga sedikit. Keberadaan jamur MVA pada tanah berhubungan dengan ketersediaan $\mathrm{P}$ di dalam tanah. Menurut Santosa (1989) ketersediaan P tanah yang tinggi akan menyebabkan menurunnya infeksi jamur MVA dalam tanah. Sesuai dengan pernyataan tersebut, bahwa kandungan $\mathrm{P}$ dalam tanah pada lokasi penelitian tergolong tinggi yaitu 14,88-43,83 ppm (Tabel 3). Yusriadi, et al. (2018) menyatakan jamur mikoriza menjadi tidak aktif apabila kondisi tingkat kesuburan tanah yang baik, terutama dengan kandungan $\mathrm{P}$ tersedia semakin tinggi. Kondisi tanah pada lokasi penelitian termasuk subur. Hal tersebut membuat jamur mikoriza yang ditemukan dalam tanah sedikit.

Faktor lain yang memengaruhi jumlah spora mikoriza adalah C-organik. C-organik merupakan kandungan bahan organik dalam tanah yang berperan dalam proses mineralisasi yang hasilnya dapat menyediakan unsur hara bagi simbiosis jamur MVA dengan tanaman dan dapat menginduksi pertumbuhan hifa (Madjid, 2009). Hubungan C-organik dengan jumlah spora searah, dimana semakin tinggi kadar C-organik dalam tanah maka jumlah spora juga semakin banyak. Muzakkir (2011) juga menyatakan nilai kandungan C-organik yang tinggi dapat menyebabkan jumlah spora jamur MVA meningkat. Kandungan Corganik pada lokasi penelitian tergolong rendah yaitu 3,05-6,88 \% (Tabel 3) sehingga mengakibatkan jumlah spora yang ditemukan sedikit.

\section{Persentase Akar Avicennia yang Terinfeksi Jamur MVA}

Adanya simbiosis antara akar dengan jamur MVA dapat meningkatkan pertumbuhan tanaman. Peranan Jamur MVA adalah dapat meningkatkan penyerapan unsur hara, meningkatkan ketahanan terhadap serangan patogen serta dapat meningkatkan ketahanan terhadap kondisi kekeringan (Rao, 1994). Hasil penelitian menunjukkan bahwa adanya simbiosis antara akar tanaman Avicennia dengan jamur MVA yang tandai dengan adanya struktur hifa, vesikula dan spora. Terbentuknya struktur hifa, vesikula dan spora menunjukkan adanya simbiosis antara akar tanaman dengan jamur MVA. Persentase infeksi akar pada tiap lokasi berbeda-beda, pada lokasi Parit Tanjung persentase infeksi akar sebesar $9 \%$, pada lokasi Kasim sebesar 11,3\%, pada lokasi Sungai Burung sebesar $8 \%$ dan pada lokasi Tanjung sebesar 14,4 \% (Tabel 2). Dari hasil persentase tersebut kategori infeksi akar pada tiap lokasi tergolong rendah.

Rendahnya tingkat infeksi akar ini dipengarui oleh beberapa faktor yang saling berhubungan. Menurut Tarmedi (2006) infeksi jamur MVA pada perakaran tanaman dipengaruhi oleh ketersediaan unsur hara dalam tanah. Ketersediaan unsur hara pada lokasi pengambilan sampel akar tergolong tinggi. Hasil pengukuran menunjukkan nilai $\mathrm{N}$ sebesar 0,34-0,74\% (tinggi), P sebesar 22,42-43,82 ppm (tinggi), dan KTK sebesar 11,75-27,03 $\mathrm{cmol}$ (+) kg-1 (tinggi) (Pusat Penelitian Tanah, 1983). Santosa (1989) menyatakan bahwa konsentrasi P tanah yang tinggi menyebabkan menurunnya infeksi jamur MVA pada akar.

Peranan jamur MVA umumnya membantu menyerap unsur hara bagi tanaman, namun apabila kandungan nutrisi tanah sudah cukup, maka jamur 
MVA mengurangi infeksi pada bagian akar tanaman. Menurut Sasli dan Ruliyansyah (2012) persentase infeksi jamur MVA pada suatu perakaran tanaman dapat dipengaruhi oleh faktor unsur hara yang terkandung di dalam tanah. Pulungan (2013) menyatakan bahwa semakin tinggi unsur hara yang ditemukan di tanah maka semakin rendah infeksi jamur MVA yang terjadi pada akar tanaman, sebaliknya semakin rendah unsur hara yang ditemukan di tanah maka semakin tinggi infeksi jamur MVA. Hal ini sesuai dengan hasil penelitian yang menunjukkan bahwa pengukuran unsur hara yang terdapat di lokasi penelitian tergolong tinggi sehingga tingkat infeksi akar Avicennia oleh jamur MVA yang tergolong rendah.

\section{DAFTAR PUSTAKA}

Brundrett, M, Dell, B, Malajeczuk, N, \& Mingqin, G, 1996, Micorrizhas for Plantation Forestry in Asia. Proceeding of an International Symposium and Workshop, Guangdong : Cina

Budiman, 2012, Keberadaan Kearifan Lokal Dalam Pengelolaan Hutan Mangrove: Studi Kasus Di Desa Peniti Luar Kecamatan Siantan Kabupaten Pontianak, Tugas Akhir Program Magister

Burhanuddin, 2012, Keanekaragaman Jenis Jamur Mikoriza Arbuskular pada Tanaman Jabon (Anthocephalus spp.), Jurnal Tengkawang, vol 2, no. 1 , hal : $10-18$

Daniels, B A, \& Skipper, H D, 1982, Methods for therecovery and quantitative estimation of propagules fromsoil

Gustian, Burhanuddin, Herawatiningsih, R, 2015, Asosiasi Fungi Mikoriza Arbuskula pada Avicennia Spp, Jurnal Hutan, vol. 3, no. 3, hal. $411-422$

INVAM, 2018, International Culture Collection of Vesicular Arbuscular Mychorrhizal Fungi, http://invam.wvu.edu/thefungi/speciesdescripti ons/, diakses 03 Januari 2018

Madjid, A, 2009, Peran dan Prospek Mikoriza. Program Pascasarjana, Universitas Sriwijaya, Palembang

Muzakkir, 2011, Hubungan Antara Cendawan Mikoriza Arbuskular Indigenous dan Sifat Kimia Tanah di Lahan Kritis Tanjung Alai, Sumatera Barat, Jurnal Solum, vol. 8, no. 2, hal. 53-57
Nadarajah P, \& Nawawi A. 1997, Vesicular-arbuscular mycorrhizal fungi in Malaysian Plantations and grasslands. Makalah dalam The International Conference on Mycorrhizas. Mycorrhizas in Sustainable Tropical Agriculture and Forest Ecosystem. Research and Development Centre for Biology. Indonesian Institute of Sciences, Bogor

Nurhalimah, S, Nurhantika, S \& Muhibuddin, A, 2014, Eksplorasi Mikoriza Vesikular Arbuskular (MVA) Indegenous pada Tanah Regosol di Pamekasan Madura, Jurnal Sains dan Seni Pomits, vol. 3, no. 1, hal. 30-34

Nursanti, Tamin, RP \& Hamzah, 2012, Identifikasi Fungi Mikoriza Arbuskular (Fma) Di Hutan Lindung Mangrove Pangkal Babu Kabupaten Tanjung Jabung Barat Jambi, Jurnal Penelitian Universitas Jambi Seri Sains, vol. 14, no. 2, hal. 29-34

Pacioni, G, 1992, Wet Sieving And Decanting Techniques For The Extraction Of Spores Of Va Mycorrhyzal Fungi, Methods In Microbiology, Academic Press Inc. San Diego, 24: $317-322$

Pulungan, ASS, 2013, Infeksi Fungi Mikoriza Arbuskular pada Akar Tanman Tebu (Saccharum officinarum L.), Jurnal Biosains, vol, 1, no. 1, hal. 43-46

Pusat Penelitian Tanah, 1983, Kriteria Penilaian Data Sifat Analisis Kimia Tanah, Balai Penelitian dan Pengembangan Pertanian Depertemen Pertanian, Bogor

Rao, NS, 1994, Mikroorganisme Tanah dan Pertumbuhan Tanaman, Edisi kedua, Universitas Indonesia, Jakarta

Santosa, DA, 1989, Teknik dan Metode Penelitian Mikoriza Vesikular Arbuskular, Laboratorium Biologi Tanah, Jurusan Ilmu Tanah Fakultas Pertanian IPB

Sasli, I \& Ruliyansyah, A, 2012, Pemanfaatan Jamur Mikoriza Vesikula Arbuskular Spesifik Lokasi Untuk Efisiensi Pemupukan Pada Tanaman Jagung di Lahan Gambut Tropis, Jurnal Agrovigor, vol. 5, no. 2, hal. 65-75

Schenk \& Perez, Y, 1990, Manual for Identification of VA Mycorrhizal Fungi, Sinergistis Publication, Gaines

Setiadi, Y, 2001, Status Penelitian dan Pemanfaatan Cendawan Mikoriza Arbuskula dan Rhizobium 
untuk Merehabilitasi Lahan Terdegradasi. Seminar Nasional Mikoriza, Bogor

Setiadi, Y, Mansur \& Achmad, 1992, Mikrobiologi Tanah Hutan, Pusat Antar Universitas Bioteknologi Tanaman Pangan, Institut Pertanian Bogor, Bogor

Sieverding E, 1991, Vesicular Arbuskular Mycorrhiza Management In Tropical Agroecosystem, Jur. Eschborn. German.

Smith SE, \& Read DJ, 2008, Mycorrhizal symbiosis, 3rd edn. Academic, London

Suhardi, 1990, Pedoman Kuliah Mikoriza Vesikular Arbusklar, Fakultas Biologi, Universitas Gajah Mada, Yogyakarta

Tarmedi, E, 2006, Keanekaragaman Cendawan Mikoriza Arbuskular di Hutan Sub Pegunungan Kamojang Jawa Barat, Skripsi, Institut Pertanian Bogor, Bogor

Warouw, V, \& Kainde, RP, 2010, 'Populasi jamur mikoriza vesikular arbuskular (MVA) pada zona perakaran Jati', Jurnal Eugenia, vol. 16, no. 1 , hal. $38-45$

Yusriadi, Dungan, Y S P, Hasanah, U, 2018, Kepadatan Dan Keragaman Spora Fungi Mikoriza Arbuskula Pada Daerah Perakaran Beberapa Tanaman Pangan Di Lahan Pertanian Desa Sidera, Jurnal Agroland, vol. 25, no.1, hal. 6473 